\title{
Editorial on the Special Issue "New Aspects on Migrant Populations in Europe: Norms, Attitudes and Intentions in Fertility and Family Planning"
}

\author{
Nadja Milewski, Eleonora Mussino
}

\begin{abstract}
This paper reviews the most recent literature on the fertility of migrant populations in Europe. In a systematic review of 21 peer-reviewed journals, we found that the literature has focused almost exclusively on actual behaviours related to the quantum and timing of births; it primarily investigates the determinants of demographic behaviour related to the structural integration of migrants. Previous literature on the demographic behaviour of migrants in Europe used factors related to culture more as a residual explanation for group differences, but it barely addressed their role specifically. The aim of our Special Issue is to draw attention to the normative side of fertility and to include aspects of reproductive health and family planning in the picture - both aspects are related to culture. This paper includes a short introduction to the articles contained in this Special Issue and proposes recommendations for future research.
\end{abstract}

Keywords: Fertility norms · Family planning · Immigrants · Second generation · Cultural integration

\section{Introduction and background}

This paper is the introduction to the Special Issue on "New aspects on migrant populations in Europe: Norms, attitudes and intentions in fertility and family planning". The papers in our Special Issue strive to answer the following research question: What are the patterns of the ideational dimension in fertility and family planning among immigrants? In order to do so the papers use different comparative perspectives, such as different immigrant generations, immigrant groups in different destination countries, or between emigrants and stayers at origin. In summarising their findings together with the literature overview, this introductory chapter deals with the challenge of answering the overarching question: What can research on fertility 
and family planning contribute to our knowledge of cultural integration processes of immigrants and their descendants in Europe?

The first section describes the general motivation behind the Special Issue. In the second section, we summarise the literature on migrant fertility based on a systematic review of 21 international, peer-reviewed and SSCl-listed journals on population studies, journals related to migration/integration, and journals on family and family planning published between 2010 and early 2018. The second section also introduces the papers of our Special Issue. In the third section, we draw conclusions from previous research and from the papers included here, leading to suggestions for future research.

\subsection{Immigration and minorities in Europe}

Recent years have seen the heterogeneity of populations in Europe increase as a result of continuing immigration. The share of foreign citizens (i.e. persons holding foreign citizenship) had increased to 11.5 percent of the population living in the EU Member States on 1 January 2017 (Eurostat 2018). In the western European and Nordic countries, which had attracted migrant workers from the 1950s to the early 1970s, the second generation is currently at the end of the family formation phase, while a third generation is coming of age. Southern Europe has evolved from a region of emigration to a destination for international migrants. Here, first-generation migrants are of family formation age and members of the second generation will soon fall under this category. While eastern European countries are destinations both for new immigrant groups and return migrants, they also have a long tradition of ethnic, cultural, and/or religious diversity (Triandafyllidou/Gropas 2007). All of these factors are contributing to a growing ethnic diversity between and within European countries. This has led to an increase in the share of births to foreign-born mothers relative to the total number of births in European countries. Consequently, the percentage figures for descendants of EU and non-EU migrants have increased, to 11.8 percent and 33.4 percent respectively, in the short period from 2008 to 2014 (Eurostat 2016). On the one hand, these developments help to mitigate the demographic challenges facing European societies, such as ageing and shrinking populations (Eurostat 2002). On the other hand, this change in the population composition has also altered the cultural composition of the "old" continent. In terms of religious diversity, for instance, the proportion of Muslims has increased from 3.8 percent in 2010 to 4.9 percent in 2016 (PEW 2017); this in turn fuels public debate on cultural differences and social cohesion between immigrant groups and non-migrant majority populations, as well as on problems related to growing social inequalities which might arise (Holland/de Valk 2013).

\subsection{Previous empirical approaches to and analytical perspectives on immigrant fertility}

In order to understand how the overall fertility trend in European countries will develop, it is necessary to understand the fertility puzzle with respect to ethnic/cultur- 
al/religious diversity, in particular the fertility differences between host populations (which are ageing and shrinking) and migrant groups (which are on average younger and increasing). Migrant fertility is a complex and interdisciplinary topic, both in terms of research on immigrant integration as well as policies related to family or/ and integration.

Demographers only began to focus on migrant fertility in Europe at the start of this century. Until then, there had been very few papers examining the childbearing behaviour of foreigners (Kahn 1994; Carlson 1985). From around the year 2000 onwards, European demographers and family sociologists have increased their interest in the fertility of international migrants, narrowing the gap with the North American literature, where this had long been a topic for both immigrant and ethnic/racial minorities. A decade ago, Kulu/Milewski (2007) argued that the increased interest in this subject was in part due to the application of the life course approach (E/der 1985) to demography.

Fertility behaviour is, on the one hand, the result of the degree to which individuals are embedded in their institutional context and of their socio-structural conditions. Therefore, some authors have suggested that fertility behaviour should also be framed as an (indirect) indicator of structural/socio-economic integration (Kulu/ Gonzalez-Ferrer 2014). On the other hand, individual fertility behaviours are strongly influenced by norms shared by the social/cultural collective(s) to which the individuals belong as well as her/his own personal experiences (Fernandez/Fogli 2006). As a result, fertility behaviours have been used to measure the adaptation process of immigrants in the destination countries, and have been framed as one indicator of cultural integration (Algan et al. 2012).

Given the relatively short time span of research interest and the fact that the available data on international migrants in Europe is rather meagre (Kulu/GonzalezFerrer 2014), the amount of published work on migrant fertility is impressive and the variation of the research perspectives is relatively rich. Some of the previous literature has addressed migrant fertility in a truly demographic style, i.e. at the macro/aggregate level, looking at total fertility rate (TFR) (e.g., Sonnino 2003; Toulemon 2004; Mussino et al. 2012) and the migrants' contribution to the overall TFR (e.g., Sobotka 2008). Some authors focused on aspects of quantum using summary measures, such as the completed fertility at the end of the reproductive period (e.g. Mayer/Riphahn 2000; Wilson 2018). Others concentrated on fertility at the individual level, applying a life course perspective to transitions to parenthood and subsequent births (Andersson 2004; Kulu/Gonzalez-Ferrer 2014).

Adopting the theoretical framework from fertility of internal migrants, research on international migrant fertility started out by comparing immigrants arriving at one destination. As awareness of differences in socio-economic compositions, cultural traditions, and legal conditions (amongst other aspects) of international and internal migrants grew, the question of within-group variation by migrant generation and country of origin arose (Milewski 2007). The intergenerational comparison became even more important as the second generation entered the phase of adulthood and their share of the total populations increased (de Valk/Milewski 2011). The approaches mentioned used the majority population in a given country as the 
point of reference for the processes of adaptation, working with the implicit assumption that immigrants may become similar to the non-migrant population, as has been proposed ever since the start of classic assimilation theory (Gordon 1964). A rather recent approach is to ask about processes of becoming dissimilar within a migrant-origin group, whether that be due to different societal conditions at different destinations (Milewski 2011) and/or the impact of the migration process which may cause differences between emigrants compared to stayers at origin (BaykaraKrumme/Milewski 2017). Consequently, the comparison between international emigrants from one country to stayers at origin and to non-migrants at their destination has emerged (Puur et al. 2017). These approaches in studying the fertility of migrants and their descendants became possible because the dissimilation perspective (FitzGerald 2012; Güveli et al. 2016) and the comparative integration context theory (Crul et al. 2012) were developed in other topics related to the consequences of international migration. Hence, data collections such as "The Integration of the European Second Generation" (Crul et al. 2012), the "Migrations between Africa and Europe" Project (Beauchemin 2018), the "2000 Families study" (Güveli et al. 2016), or EURISLAM (Hoksbergen/Tillie 2015) were initiated and offered new opportunities for analysis.

Kulu/Gonzalez-Ferrer (2014) gave a comprehensive overview of the theoretical approaches and the empirical research carried out to date on migrant fertility in Europe, thereby opening up a discussion of opportunities for future research. They concluded that the fertility behaviour of international migrants and their descendants differs from that of the populations at both destination and origin. However, controlling for demographic and socio-economic characteristics mitigates differences between non-immigrants and immigrants from high-fertility countries. As a result, they suggested concentrating on the impact of the institutional context.

\subsection{The ideational dimension in minority fertility}

Interestingly and surprisingly, however, almost all papers on migrant and minority fertility in Europe study this topic in the very strict sense of demographic behaviour, i.e. the timing and quantum of births. Actual fertility behaviour may be the result of family preferences, but also of the actual socio-economic conditions in which fertility decisions are embedded. Changes over time or in the life course, or differences in fertility behaviour between groups may reflect social inequalities and these may or may not be accompanied by differences or (preceding) changes in norms. When investigating fertility behaviour, it is hard to draw conclusions as to whether the cause of fertility differentials between migrants and non-migrants or between migrant groups is related to socio-economic or cultural factors, and the interaction between culture and structure (Glick 2010). Cultural differences, cultural entrenchment (Forste/Tienda 1996), socialisation into a "sub-culture" (Milewski 2010), or "cultural maintenance" (Abbasi-Shavazi/McDonald 2000) are often given as a residual explanation of remaining differences between different ethnic or migrant origin groups (Kulu/Hannemann 2016). Accordingly, in the case of similarities between different origin groups the conclusion drawn indirectly from the results is "cultural" integra- 
tion. But a true test for the hypothesis of cultural diversity in migrant fertility is still lacking.

In this Special Issue, we include two aspects in which culture and fertility are intertwined: 1) There are the norms and attitudes related to the number of children a person should have in her/his lifetime, i.e. the ideational dimension of fertility. Studies of demographic behaviour faces the question how to include immigrants with children born prior to the move into the analyses because the can obviously not adapt to the destination context or only in higher parities. Usually, the exposure time and births that occurred before the move are excluded from the analyses. The study of the ideational dimension, however, allows to include immigrants with premigration births into the picture. 2) Culture shapes how norms and attitudes are translated into intentions and how fertility intentions are realised; i.e. methods of reproductive health and family planning. This includes the questions of whether the arrival of a child should be planned or not and under what conditions a child should be born. Today, people in the West are used to the notion of planned parenthood. This requires a conscious decision to have a child and is regarded as the only responsible way in which children should arrive. The link between marriage and childbearing has become less strong. By contrast, in less industrialised countries, there are major differences in the use of family planning. Particularly in rural areas, in poorer contexts, and among those persons with a lower level of education, children may "just arrive" in the absence of (effective) contraception, and do so mostly within the framework of marriage. Such cultural aspects, which may be highly intertwined with socio-economic factors and the availability of reproductive health care services - methods of reproductive health and family planning as well as norms and attitudes - have hardly been investigated in the previous literature on migrant and minority fertility in Europe.

For international migrant groups, norms, attitudes and values regarding sexuality and family are seen as indicators of cultural integration processes (Ka/mijn/ Kraaykamp 2017). Consequently, rather than focusing solely on socio-economic determinants - regardless of whether this is the desired number of children, the ideal family size, childbearing intentions or expectations - attitudes should give us a better understanding of the cultural embeddedness of migrant fertility. Already 10 years ago, Testa/Grilli (2006) emphasised the lack of reflection on the ideal family size for the majority populations in Europe. Fertility ideals and desires may be relatively "soft" predictors (Sobotka/Beaujouan 2014) of the actual fertility behaviours, but they may be a better reflection of personal norms than of actual behaviour (Testa/Grilli 2006; Kuhnt et al. 2017) and may also allow for a better conclusion on the role of the normative context for fertility behaviour (Testa/Grilli 2006; Thomson 2015). Furthermore, many of the studies of the majority populations' desired number of children justified their research interest by assuming there to be a gap between the number of children that are desired and realised respectively in the context of European welfare states, which are characterised by population ageing and do not reach replacement fertility levels. This assumed gap between desired and actual numbers is also given as a reason to implement social policies directed at gender equality and the reconciliation of family and work life (Touleman/Testa 
2005). Such a fertility gap and potential policy implications have only been scientifically studied for members of the majority populations in European welfare states and not for immigrants. One reason for the omission of migrants from these research questions may be that immigrants were shown to have higher average fertility than non-migrants and that researchers may think that migrants therefore do not require further support. Another reason for this omission of migrants may be that the percentage of immigrants in European countries is increasing and there is growing concern about social inequalities in both politics and public discourse. This may, in turn, pose a challenge to social cohesion and increase conflicts between the groups. Measures that are designed not to hinder the realisation of fertility for the immigrant population may therefore seem a very sensitive topic.

Accordingly, much of the previous literature on migrant integration has focused on human capital (i.e. education) and on economic aspects such as labour market participation, wages or poverty (e.g. Kogan 2003; van Tubergen et al. 2004; Penninx 2005; Kes/er 2006). In the past few years, however, the political debate as well as research on structural integration has begun to include cultural aspects (Algan et al. 2012). Yet, the question as to what constitutes "cultural integration" remains open. The concept of cultural integration has been used to frame actual behaviour, such as intermarriage, language spoken at home, or educational achievement (e.g. Gordon 1964; Coleman 1994; Wilson et al. 2011), or to measure the difference between immigrants and native-born persons in terms of cultural habits, values, and beliefs, such as religiosity (Diehl/Koenig 2009), attitudes toward gender equality (Dieh/ et al. 2009; Spierings 2015; Mussino et al. 2018), or language proficiency (e.g. Caselli 2015; Mussino et al. 2014).

The main goal of this Special Issue is to focus on cultural aspects in the study of demographic behaviour among migrant and minority groups in Europe. We extend the literature first by adding the ideational or normative dimension, i.e. childbearing intentions and ideal family size, to the topic of fertility. Second, we include aspects of family planning in the picture, i.e. attitudes towards abortion and assisted reproduction. We use different comparative perspectives to explore the within-group variation among migrant populations by including the first and second generations, by comparing stayers at origin to emigrants at destination, and migrants in different destinations in order to disentangle the roles of selection, disruption, and adaptation. While most of the previous studies have focused on women, we also devote attention to both sexes. The regional focus of the Special Issue is Europe. These papers examine new immigration contexts (e.g. Italy) and include eastern Europe (Russia, Estonia), where ethnic and religious minority groups have a longer tradition than the comparatively young immigrant minorities in western Europe. This allows us to extend theoretical considerations over a longer timeframe and to generalise from migrant minorities to minorities of any particular ethnic/cultural origin. 


\section{Previous literature and the contributions of this Special Issue}

\subsection{Review summary}

Our literature review spanned the period from 2010 to the beginning of 2018 and looked at 21 peer-reviewed journals (see Appendix Tab. A1). These cover subjects in demography and population studies in general, or focus explicitly on migrants and ethnic minorities, or on family and family planning. In selecting the journals, we followed the example of Kulu/Gonzalez-Ferrer (2014) but extended the list by adding journals on family planning. The time span covered a part of the review of Kulu/Gonzalez-Ferrer, but the years since the publication of their work were added. We found and explored 111 papers, about two thirds of which investigated topics of migrant fertility, while the remaining third addressed topics relating more to family planning, sexual behaviour and reproductive health. Most of these papers were empirical studies based on quantitative data and methods. Our literature also covered migrant and ethnic/racial minorities in the traditional countries of immigration, not only Europe.

The subject of immigrant fertility in a demographic sense (i.e. the timing and quantum of births) is treated primarily in those journals that cover population developments; about 80 percent of the papers appeared in these journals. Migration journals and general family journals each accounted for only about 10 percent of the papers on migrant fertility. Migrant fertility has become a "European" topic; about three quarters of the papers focus on western Europe and to a very small extent on eastern Europe, whereas only one quarter focus on the United States, Canada, or Australia. In accordance with this finding, the analytical groupings being studied are mainly "migrants and their descendants", and, to a lesser extent, "minorities", be they racial, ethnic, or religious minorities. In Europe, Canada, and Australia, the origin groups being studied are mainly work migrants and their descendants, in particular those from non-Western countries, minorities from former colonial regions (as in France, the Netherlands, and the United Kingdom), or from neighbouring countries (such as in the Nordic countries or the states belonging to the former Soviet Union). In the United States, these are mainly racial or ethnic minorities, i.e. blacks and Latinos. In terms of migrant fertility subjects, around 90 percent of the papers investigated behaviour; in this literature review we found only 10 papers that dealt with the ideational dimension of the subject. Among the topics covered, birth transitions stand out in terms of fertility behaviour. Interestingly, the application of the life course approach and techniques of event history analysis are a "European" approach because this is found mainly in studies on European destination countries; this coincides with the emphasis on the migration process with both childbearing and moving as life course events. This also shows that minorities are framed mainly by their migrant origin in the European context. By contrast, macro measures (TFR, period TFR) were analysed mainly in the North American context. Summary measures (completed number of children) were a subject in both regions.

Unlike migrant/minority fertility, the subject of migrant family planning is a topic mostly covered in family journals (about three quarters of the papers were pub- 
lished in such journals), to a limited extent in demographic journals, and hardly at all in migration journals. It is an overwhelmingly North American topic and deals primarily with ethnic/racial groupings. Among the topics covered, contraception ranks highest, featuring in about 55 percent of the articles, followed by studies related to sexual activity, including sexual partnership histories (50 percent). Other topics covered were induced abortions and unexpected/unwanted pregnancies (both less than 10 percent each). In this area of study, the percentage of papers focusing on attitudes is about one third as opposed to two thirds that investigate behaviours.

When we consider these two fields of research topic - fertility and family planning - as well as the behavioural and the ideational dimension together, fertility behaviour clearly dominates the literature. While this is not surprising, we want to point out that the topic of family planning is almost a blind spot in the current literature on migrant and minority groups in Europe.

\subsection{Fertility intentions and family size/number of children}

Actual fertility behaviours may be mediated by or appear as the result of different socio-economic factors (Miller/Pasta 1995; Ajzen/Klobas 2013). In this Special Issue, we therefore promote the idea that fertility preferences may be a more appropriate indicator of cultural integration because these are more representative of underlying norms and ideology. When addressing the topic of "fertility preference", however, we need to consider the variety of concepts, such as the desired number of children, personal ideal family size, intentions, or expectations.

Fertility intentions, usually measured as short-term parity-progression intentions, are generally considered to be relatively concrete, even if they are susceptible to change over time and based on previous experiences (Namboodiri 1983). Although fertility intentions have been considered the most accurate measure of predicting fertility (van de Kaa 2001), the fertility intentions of immigrants and their descendants have been the subject of hardly any studies, either theoretical or empirical. There are a small number of exceptions in the form of US studies that look at fertility intentions and outcomes, including unintended pregnancy or fathering, in particular for Latinos (Sorenson 1985; Rocca et al. 2010; Hartnett 2014; Daugherty 2016). On the one hand, Hartnett (2014) looked at aggregate measures and found that Hispanics come closer to achieving parity intentions compared to non-Hispanic whites. On the other hand, at the individual level, Latinos are not more likely to meet their intentions.

Our Special Issue includes two papers on fertility intentions in two European contexts. Erik Carlsson uses data from the Swedish Generations and Gender Survey (GGS) to investigate the short-term fertility intentions of immigrants and their descendants in Sweden (Carlsson 2018). His study sought to test whether immigrants adapt their fertility intentions towards the Swedish level over generations, and whether such intergenerational patterns vary by gender and regional origin. The results of Carlsson's study suggest that the pattern of adaptation across migrant generations, which is usually found in the literature on actual birth behaviours, also appears with respect to the ideational level of fertility. Whereas the first genera- 
tion's fertility intentions are increased as compared to non-migrant Swedes, the intentions of persons belonging to the generations 1.5 or 2 are rather similar to those of Swedes. However, this process varies among origin groups. Cultural proximity seems to play an important role in the process of generational change: the greater the cultural difference between the migrants' country of origin and the destination (i.e. Sweden), the slower the process of cultural integration.

The second paper on fertility intentions included in this Special Issue looks at the Estonian context; Allan Puur, Hanna Vseviov and Liili Abuladze use an origindestination perspective to compare the fertility intentions of Russian emigrants and their descendants in Estonia relative to non-migrants in Estonia and to stayers in Russia (Puur et al. 2018). They use data from the Estonian and Russian GGS and focus on women. Their research question is which individual and contextual factors may promote or hinder the convergence of the fertility levels of migrants and their descendants with those of the host society. Unlike the Swedish case, Puur et al. find evidence of cultural maintenance among the Russian emigrants and their descendants in Estonia, who have fertility intentions which are more in line with those of their counterparts in Russia and different to the respective intentions of the non-migrants at destination, i.e. Estonians. However, convergence of the fertility intentions of immigrants and their descendants with those in the host country is greater if the immigrants and their descendants are also integrated into other aspects of the host society, such as being proficient in the host country language and having a partner belonging to the majority population. As was the case with the paper by Carlsson on Sweden, this finding indicates that cultural embeddedness does matter.

Unlike the measures of fertility intentions, the more normative aspect of fertility preferences can be measured by "softer" indicators, such as the desired or the ideal number of children (Sobotka/Beaujouan 2014). These indicators generally express quantum preferences without a specified timeframe (e.g. Thomson 2015). Desires have been linked to more internal and personal norms (Testa/Grilli 2006; Kuhnt et al. 2017), because by their nature they are often uncertain and subject to change over the life course (Thomson 2015). In our systematic literature review, the only paper that we found since 2010 which referred to migrants is that by Kraus/Castro-Martín (2018) on the Latin American 1.5 generation in Spain. The authors investigated fertility expectations and did not find any difference in the expected family size between adolescents of migrant and non-migrant origin. With regard to the expected age at childbearing, however, they found that fertility timing preferences of Latin American adolescents were influenced by the society of origin; their expected age at first birth was between that of their Spanish peers and that prevailing in their country of origin in Latin America. These findings point to a relatively rapid adaptation of migrant children to the childbearing norms in the host society.

Personal ideals, which are expressed under "ideal conditions", are another indicator used to measure the ideational dimension of fertility. These are assumed to be unaffected by other constraints and are also assumed to be more stable over time (Philipov/Bernardi 2011; Thomson 2015). Consequently, fertility ideals have been interpreted as reflecting the normative context (Trent 1980; Testa/Grilli 2006). This is why the study of the personal ideal family size of immigrants presents a promising 
and (to date) underdeveloped opportunity when it comes to disclosing the relationship between migration and fertility. In a descriptive paper, Penn/Lambert (2002) showed how different ethnic groups or migrants in different destination countries exhibit differences in their preferred timing for family formation. Differences were also found in the Netherlands in both the ideal age at childbearing and the family size among ethnic group origins (de Valk 2013), which suggests that the migrants' childhood socialisation at origin has a lasting effect on fertility ideals. At the same time, there were significant intergenerational differences in the ideal family size among all the groups, with migrant children preferring a smaller family size than their parents, indicating that adaptation processes are at work. Some evidence of a socialisation effect by country of origin was found for Sub-Saharan African migrants to France regarding their fertility ideals (Afulani/Asunka 2015). In the British context, Berrington (2018) looked at expectations for marriage and parenthood and confirmed the persistence of large ethnic differences in expectations for family transitions, with important divergences within the south Asian communities. Holland/ de Valk (2013) looked at ideal ages for marriage and parenthood among immigrants from over 160 countries of (parents') origin living in 25 European countries. They found that origin influences the ideal of only the most recent migrants in terms of age of parenthood.

One paper in our Special Issue focuses on fertility preferences, using the personal ideal family size among immigrant women in Italy. Eleonora Mussino and Livia Ortensi estimate the personal ideal family size of immigrant women in Italy using data from the ISTAT survey entitled "Social condition and integration of foreign citizens", which was conducted in 2011-12, and they compare it with the prevailing norm of stayers in their country of origin (Mussino/Ortensi 2018). They analyse determinants of agreement and disagreement with the Italians' norm testing of the hypothesis of cultural socialisation being maintained against the hypothesis of adaptation. The authors find that the country of origin plays an important role in the determination of immigrants' ideal family sizes. They conclude that cultural socialisation, measured both with the effect of country of origin and age at arrival, explains the persistence of the personal ideal family size norm. Furthermore, they suggest that the processes of convergence observed in actual fertility among firstgeneration migrant women in Italy might be due primarily to financial restrictions or other disruptive phenomena rather than to a real and deeper change in fertility ideals. In line with this result, the time since migration has no significant impact on the match between personal and average family ideals of the country of origin. The authors conclude that it is hard to understand whether or not migrant's ideals were inconsistent with those of their country at the migration stage (selection) already or whether they changed in the destination country, but they conclude that if migration drove the change, the effect is not time-dependent.

\subsection{Birth control and abortion}

In our systematic review of literature since 2010, contraception was the second major topic addressed in the field of migrant and minority fertility. About a third of the 
papers included topics on attitudes towards, utilisation of, satisfaction with, and knowledge about contraceptives. By contrast, the number of publications on induced abortions was three in absolute terms out of approximately 100 papers, all of which dealt with actual behaviour and none on attitudes towards abortion. Some of the papers on contraception, however, mention the connection with abortion as they conclude that the use of (effective) contraception may prevent abortions ( $K u$ sunoki et al. 2016). However, other papers relate the absence of (effective) contraception to higher risks of sexually transmitted diseases (e.g., Deardorff et al. 2010), higher fertility (White/Potter 2013), higher risks of unintended pregnancies and related social problems (Jacobs/Stanfors 2013), or barriers in health care service access (Dehlendorf et al. 2011). Almost all of the papers on contraception focused on the North American context; only one study investigated a European context looking at contraception and abortion (Agadjanian/Hyun Yoo 2018).

Empirical evidence on abortion is scarce because any research on the subject requires sensitive questioning, and because abortion is not permitted at all in some countries (Bankole et al. 1998). In general, the incidence of abortion is higher in East Asian countries than in Europe and North America. Within each of the continents, there is considerable variation between countries, however. In Europe, the abortion rates are lowest in countries in the west and north of the continent, but they are higher in southern Europe, with the highest rates estimated for countries in eastern Europe (Sedgh et al. 2016).

Attitudes towards abortion are most conflicting in regions where induced abortions are illegal or legal only on specific grounds, which coincides with higher incidence rates in these regions (WHO 2005). Hence, certain immigrant groups in Europe originate from regions where the risks of an induced abortion are higher than in the majority population at destination, while at the same time the immigrants may hold less liberal attitudes towards abortion. Two studies by Helström et al. (2003 and 2006) showed that the abortion rate was significantly higher among various immigrant groups in Sweden. They explained this finding as the sum of various risk factors, such as low education, a weak social network, poverty, unemployment, and being outside common pathways to health care (He/ström et al. 2003). They reached a similar conclusion for teenage girls (Helström et al. 2006). Both studies showed that the utilisation of contraceptive methods was lower in immigrant groups. By contrast, immigrants to Russia - a societal context with rather high abortion rates overall - were found to have lower abortion rates, but there was variation by their legal status (Agadjanian/Hyun Yoo 2018).

The findings regarding contraceptive use and abortion risks in relation to migrants to Europe are similar to the large body of empirical evidence on migrant and racial minorities in the US - even though the minority and majority groups in both continents are different in terms of their ethnic composition, their religious composition and adherence to religious beliefs, and even though the policies regulating access to birth control and abortion and the access to the health care systems are different too. The minority groups are found to use contraception to a lower extent (Poncet et al. 2013) and to have induced abortions more often than women of the majority populations. 
The low degree of contraceptive use is, however, not the only reason for elevated rates of abortion in immigrant groups. In a qualitative study, based on in-depth interviews, Puri et al. (2011) found for Indians in the US that induced abortions were a means of sex selection. Indian immigrants maintained their son preference after migration. Indirect evidence of sex-selective abortion among immigrant populations has also been found in other contexts, indicating elevated skewed sex ratios at birth, especially for higher-order births (see Dubuc/Coleman 2007 for the UK; Almond/Edlund 2008 and Abrevaya 2009 for the US; Singh et al. 2010 for Norway; Verropoulou/Tsimbos 2010 for Greece; Ray et al. 2012 and Almond et al. 2013 for Canada; González 2014 for Spain; Ambrosetti et al. 2015 for Italy; Mussino et al. 2018 for Sweden).

Almost all of the articles included in our systematic review of 21 journals that dealt with abortion were on aspects of behaviour and prevalences, and focused on the North American context. Only one paper investigated attitudes towards abortion among international migrants in Europe. Carol/Milewski (2017) showed that both religious affiliation and individual religiosity influence Muslims' attitudes towards abortion. Moreover, many of these attitudes are maintained from one generation to the next.

The paper by Nadja Milewski and Sarah Carol included in this Special Issue investigates attitudes towards abortion among descendants of Turkish migrants and descendants of non-migrant parents in six European countries (Milewski/Carol 2018). The authors used data from the project on The Integration of the European Second Generation (TIES). Unlike in other surveys, the question regarding attitudes towards abortion in the TIES questionnaire distinguished between "medical" and "non-medical" reasons for abortion. Their results show that both groupings that formed the subject of the study expressed a range of attitudes, and that abortion for medical reasons was more accepted than abortion for non-medical reasons. However, the Turkish descendants were more likely than the non-migrants to say that they would never accept abortion, and there was variation by country of residence. The authors conclude that attitudes toward abortion among Turkish descendants are influenced by their family backgrounds, but also by their socialisation experiences in receiving countries in Europe. These findings suggest that processes of cultural integration are occurring, but not the point where the attitudes of migrants have converged with the attitudes of non-migrants in the respective destination country.

\subsection{Assisted reproduction}

A topic that has not entered the migrant/minority fertility literature yet is the question of unfulfilled fertility intentions. In our literature review, we did not find any papers on assisted reproductive technologies (ART) in the context of international migrants or ethnic minorities, neither on the ideational nor the behavioural dimensions. In the research carried out on the general populations, ART plays an increasing role in work on health care policies and fertility (Präg/Mills 2017a). This is due on the one hand to growing possibilities in the reproductive health care sector. On the 
other hand, the assumed gap between fertility intentions and realisation plays a role in a general societal climate where fertility seems to be too low and may be viewed as needing to be increased at the level of the population. Accordingly, the literature focuses on legal conditions, cross-country variation in use, and on the question of the contribution of ART-related births to the TFR (Präg/Mills 2017a).

Previous literature on cross-country variation in ART use brought up cultural factors as one of the possible explanations for these differences. Beliefs about the moral status of an embryo may play a role. In countries where fewer people think that the embryo becomes a human being immediately after fertilisation, the rates of ART use are higher (Präg/Mills 2017b). If there are cultural differences in the use of ART, the question arises as to whether attitudes regarding ART would also vary between immigrants and the majority population in a given country. Previous research on attitudes towards ART has been scarce, however.

The study by Sonja Haug and Nadja Milewski in this Special Issue examines attitudes towards ART among immigrant women and non-migrants in Germany (Haug/ Milewski 2018). The analysis is based on data collected in a pilot study conducted in 2014 and 2015. The sample includes 960 women aged 18 to 50 who originate from Turkey, Poland, the Balkan countries, countries of the (Russian) Commonwealth of Independent States (CIS), or Germany. The authors study the social norm to use ART to have a child, the personal attitude of whether a woman would use ART herself, and the methods that they would consider for their own use. The results show that the majority of women would use ART if necessary. There is significant variation between the origin groups, however. Non-migrants show the lowest acceptance rates and migrants from Poland and Turkey the highest approval. There is also variation in the ART procedures considered for use with the migrants more approving of heterologous methods than non-migrants. The differences between the origin groups diminish only partly when controlling for further explanatory variables, i.e. gender-role attitudes, religiosity, and socio-demographic characteristics of the respondents. Haug/Milewski conclude that attitudes towards ART are shaped less by socio-demographic characteristics, but rather by cultural factors and socialisation in the migrants' countries of origin.

\section{Discussion: Conclusions and implications for future research}

Our Special Issue extends the research field of migrant fertility in Europe to include the thematic aspects of ideals, attitudes, and intentions in fertility and family planning in Europe. In this section, we draw conclusions from the papers in our Special Issue and discuss implications for future research.

First, we showed that the ideational dimension in fertility deserves scholarly attention. If conclusions are drawn only from fertility behaviour, the previous research leads us to deduce that immigrants on average adapt quite quickly (i.e. within one generation) to the behaviour of the respective majority population at destination. The main factors behind the rather fast process towards convergence were attributed to socio-economic conditions (e.g. Andersson/Scott 2005, 2007), and conver- 
gence in fertility behaviour was interpreted as an indicator of adaptation, assimilation, or cultural integration. Cultural factors - although often unobserved - were put forward as an explanation for persisting gaps between certain immigrant groups and the majority populations. The papers included in this Special Issue confirm, on the one hand, the role of socio-economic conditions too, because controlling for such factors also reduces the differentials in fertility attitudes between immigrants and the majority population. On the other hand, substantial differences between these groupings remained, and these gaps seem somehow persistent in attitudes more than in studies on actual behaviour. In general, it seems that there is also a gap between the desired and the realised number of children, as far as migrants are concerned. Moreover, converging levels in actual fertility behaviour seem to be the result of socio-economic processes, which might not be accompanied by changes in cultural attitudes or customs. The question arises as to why such gaps between intention and realisation occur and whether the reasons differ between migrants and members of the majority populations. Possible answers here include the longer time it takes to find a partner due to the discrimination of certain immigrant groups (E/wert 2018), higher opportunity costs for minority group members, in particular women, who have achieved a higher level of education and an above-average occupation; this has been proposed in the literature as the minority status hypothesis (Milewski 2010). In order to address the question of the fertility gap properly, future research needs to study both intentions and realisation in one sample, not in separate studies.

Since the papers included in this Special Issue examined different institutional contexts, we can also conclude that this gap between immigrant/minority and majority groups varies depending on the institutional context of the countries of residence. In a country where social policies are geared heavily towards fertility, family life, and labour market activity (Sweden), the minority-majority gaps seem narrower than in a country where there is a relative absence of welfare policies (Russia).

However, it should be noted that immigrants from countries with higher fertility rates show a convergence with majority fertility levels (actual behaviour) somewhat sooner in countries with higher fertility levels than in those countries with lowestlow fertility. This is because the difference between origin and destination is smaller, e.g. when immigrants move to a Nordic country as compared to the Mediterranean. The same logic applies to the study of the ideal or desired numbers of children or fertility intentions. As a result, the comparison between emigrants and the stayers at origin is important in order to gain a full picture of processes of adaptation to destination and dissimilarity from origin. The paper by Puur et al. showed that fertility intentions among emigrants are quite similar when compared to the stayers at origin, with little difference between the migrant generations. This suggests a high degree of cultural maintenance and intergenerational transmission of the norms and attitudes acquired during socialisation in the country of origin.

It should also be noted that other aspects of fertility and family behaviour, such as the timing of births, birth spacing, or the association between marriage and childbearing, were shown to vary by immigrant origin group, societal context of destination, and migrant generation. At the same time, the pace of adaptation varies for 
these aspects. In general, the conclusion that can be drawn from the literature is that adaptation processes occur faster in the behavioural dimensions of fertility and family dynamics, whereas the impact of cultural socialisation may be longer lasting. Hence, socio-economic factors serve as adaptation channels - while diversity in attitudes towards culture persists.

Second, planned vs. unplanned fertility: Another aspect arising from the work presented in this Special Issue is the question regarding the extent to which fertility is the result of rational family planning, which is also related to cultural socialisation. Mussino/Ortensi analysed not only the numbers given for the question on the ideal size of the family, but also the occurrence of non-numeric responses ("family size is up to God"; "don't know"). The share of such responses is rather high, especially among some immigrant groups. Hence, this finding poses another question, namely whether women originating from different settings express numeric preferences in the same way? Early surveys (i.e. those conducted in the 1970s) in high-fertility contexts had prompted concern about the usefulness of asking questions about intentions and preferences. In countries that had not yet undergone the transition to controlled fertility, demographers hypothesised that childbearing was not normally the subject of individual decision-making, especially for women. In such settings, it was unclear whether women would be able to formulate preferences or to consider childbearing goals under hypothetical conditions. A series of studies reacting to these concerns examined and largely confirmed the overall validity of reported family size preferences (Hayford/Agadjanian 2011). This leads to the conclusion that the numeric answers are also valid for women from "transitional" fertility contexts. However, the categories "I don't know" or "it's up to God" may reflect the notion that respondents choosing these answers do not "plan" parenthood. These respondents are usually excluded from the analyses, which focus on the gap between desired and realised numbers of children. If the share of respondents who are unable to attach a number to their fertility ideals or desired family size is higher among migrants than among non-migrants, the results for the group differences are likely biased. Future research should be aware of such a bias and try to estimate how many children these people had at the end of their reproductive life span.

Third, other cultural aspects: Like the work on actual fertility behaviour, the papers included in this Special Issue showed variation within the migrant populations. The papers that compared migrant generations delivered evidence of the "in-between position" of the migrant descendants - depending on the cultural distance and the differences in fertility between origin and destination contexts. One of the crucial issues will be whether a certain immigrant group in a certain country develops into a minority group and how cultural and structural/socio-economic factors interact with each other (Glick 2010). Minority groups and immigrant groups may overlap or be distinct from each other; or a group of migrants may develop gradually into a minority group over time and generations (Coleman 1994). Bean and Tienda (1990) listed four criteria, which together characterise minority groups. These are as follows: 1) each of the sub-groups constitutes only a small proportion of the total population of a country; 2) members of the particular group experience a sense of self-awareness as belonging to the group; 3) members of the particular 
group experience a degree of discrimination by members of the majority group; and 4) the members of the particular group are to some extent discernible in their appearance as its members.

From a demographer's point of view, a distinct demographic behaviour is the fifth characteristic of a minority group. The question is which migrant groups turn into a minority, with distinct patterns of fertility and family formation (and which do not) and why? What constitutes such a sub-culture, and how is this sub-culture transmitted from one generation to the next? In this regard, the papers in this Special Issue suggest that attitudes and intentions in fertility and family planning matter. Future research should therefore include more measures of culture in order to estimate its impact on demographic behaviour. The papers by Haug/Milewski and Milewski/Carol suggest that religious affiliation and religiosity may be better predictors of group differences than a category that accounts for the rather broad "migrant background" or "country of origin". The question of which indicator is useful will become more important in the next migrant generations, i.e. generation 3+, when migration-related variables such as the country of birth or the year of the international move will no longer work because these generations are not affected by the migration event of their ancestors anymore. Instead, they are affected by socialisation into a minority culture and/or the experience of discrimination and inherited socio-economic inequalities.

Other items that deserve attention in order to understand the cultural side of migrant and minority fertility are norms and attitudes towards the relationship between marriage and sex. Non-marital childbearing was shown to be less common in certain migrant groups than in the respective majority populations in Europe (Carlson 1985), mainly in groups originating from countries where marriage is almost universal and childbearing is exclusive to marriage, such as countries with a Muslim tradition. Few studies, however, focus on migrants from countries where matriarchal family traditions persist (such as in the Caribbean) or where the connections between marriage, sexual intercourse and childbearing are not as strong (such as for migrants from Sub-Saharan Africa). They suggest that the patterns of marriage and childbearing continue, at least to a certain extent, even after migration (Kulu/ Hannemann 2016). In addition, literature on minority groups in the US focuses on early sexual debut, the below-average use of contraceptives, and high teenage birth rates, which result in a rather high risk of unintended pregnancies and lone motherhood in the absence of a strong marriage norm. By contrast, in minority groups that emphasise the norm of virginity at marriage and where marriage is the dominant living arrangement, an early entry into motherhood would be less associated with social problems. In order to understand the association between marriage and family formation, such as the age at first childbirth, it is necessary to look at the norms regarding the relationship between sexual activity and marriage, the interplay with other processes in the transition to adulthood - such as leaving the parental home and marriage (Milewski 2010) - as well as the age norm at first childbirth (Holland/ de Valk 2013).

Fourth, aspects of gender roles and gender-role attitudes: The papers included in this Special Issue address the role of "gender" - which is also highly intertwined 
with culture and cultural differences - in fertility and family planning in several ways. The inclusion of both women and men in Carlsson's paper is of additional value, not only for research on fertility intentions, but also for research on immigrant fertility in general as hardly any attention has been paid to men's fertility in previous literature. Carlsson shows that men and women of the first migrant generation do not significantly differ in their higher-than-non-migrant intentions. By contrast, gender differences appear in the generations 1.5 and 2; while migrant women state similar intentions to the majority group, migrant men are more likely than majority group men to state a positive fertility intention. This suggests that migrant women adapt to the socio-demographic context at destination more quickly than men. The question remains as to why these gender differences occur. We may speculate here that the (opportunity) costs for children are higher for women than for men, and therefore adaptation appears faster among migrant women than men. Mussino/ Ortensi and Haug/Milewski illustrated that attitudes towards gender equality also shape fertility attitudes and account for differences between immigrants and nonmigrants in Europe.

Sex preferences for children is another aspect worth studying. Signs of support for traditional ideals related to fertility have also been found regarding sex preference for children: an example in this sense is the persistence of a preference for having a boy, as evidenced by the imbalance in sex birth ratios among immigrants from selected backgrounds (e.g. Ambrosetti et al. 2015; Mussino et al. 2018). Moreover, the topic of sex preferences for children should also be implemented in questions on attitudes. The "European" preference seems to be to have one child of each sex; families who have two children of the same sex were found to be more likely to have a third child even if in some Nordic countries there is a shift towards a preference for having a girl (Andersson et al. 2006, 2007; Miranda et al. 2018). However, certain immigrants originating from countries where the norm is to have at least one son, exhibit a higher and faster transition rate to having a third child if the first two children were daughters (Hampshire et al. 2012; Lillehagen/Lyngstad 2018; Mussino et al. 2019).

So far, previous research in Europe investigated the actual sex ratio in a given population or the transition to a subsequent child controlling for the sex of the previous child(ren). The conclusions drawn still remain somewhat speculative; the gap between preferences and actual offspring composition may be greater than measured in behaviour. The decision of parents to have another child may be driven not only by their preferences and by the sex composition of the previous children, but may also be influenced by socio-economic conditions, union/family history, biological ability and the experiences of previous births (to give just a few examples). Hence, the direct question on preferences would reveal the extent of the gap in the sex preferences for children between minorities and majority populations, but also within the immigrant population. The question of sex preferences is central to attitudes towards gender roles - gender equality is one of the core elements with which European societies identify themselves and differential sex preferences for children seem to contradict this identity and the notion of gender equality. 
Fifth, family planning methods: Another research topic that is interesting to study is the question of family planning methods, i.e. what methods of contraception are used and how unintended pregnancies are perceived. It seems likely that persons who do not "plan" to have children do not use contraceptives or start using them only after a certain parity. We think it likely that this heterogeneity will also lead to growing disparities in unintended pregnancies and the resulting consequences, such as negative health and developmental outcomes for mothers, children and families (Hayford/Guzzo 2013). Studies on the US showed that the rates of unintended pregnancies and induced abortions are disproportionally higher among blacks than among whites, and that racial and ethnic differences in fertility persist even after socio-economic characteristics and relationship status are accounted for (Barber et al. 2015). This is largely because, relative to white women, black women had higher rates of sex without contraception in adolescence and partly because they are more likely to have grown up with a single parent (Barber et al. 2015).

In order to understand the processes, meanings, and motivations for cultural maintenance or changes in demographic behaviour of immigrants, it is not sufficient to count numbers, be it either the desired or the realised number of children. It is also necessary to understand how these numbers are "achieved". In this regard, birth control arises as a topic. Future research on migrant fertility and cultural integration should also look at attitudes towards and the use of contraception because contraception and abortion are interrelated (Miller/Valente 2016). Access to both contraception and abortion are reproductive rights that are central to women's self-determination and gender equality. If migrant women in the new destination context are to gain access to equal opportunities (even gradually over generations), this topic deserves special attention in policies, education, and research on gender equality and public health. Related to the attitudes towards family planning and the use of contraception is the question of knowledge and access. Clearly, methods of contraception, assisted reproductive technologies, or health care services for induced abortion can only be used when there is knowledge about the availability thereof and when there is access thereto.

It is now clear that the heterogeneity of migrants to Europe as well as between European countries is already quite substantial and is growing. As we emphasised the importance of cultural assimilation and specifically attitudes, norms, and intentions on fertility as well as on family planning practices, the respective questions obviously need to be included in data collections as well. To date, some of the topics that we suggested for study are barely included in data collections at all, such as attitudes towards abortion or assisted reproduction. These topics would be interesting for both minority and majority groups because huge variations in attitudes are also apparent among the majority populations. Other topics, such as the question of planned parenthood or contraception, seem to have disappeared from the European research agenda. As far as immigrants from countries where modern contraception is not available are concerned, the question arises as to whether they adapt to reproductive health issues in Europe. An effort should therefore be made to also include such items in data collections. 
Coming back to our research question, we end this introductory chapter by concluding that fertility can serve as a good indicator of immigrants' integration only if both socio-economic and cultural aspects are taken into account. First, studies on fertility behaviour with respect to timing and numbers should be complemented by the ideational dimension, such as norms, attitudes and intentions, the possible gaps between behaviour and intention as well as the reasons for such gaps. Second, the practice of family planning and family formation should be investigated in more detail, e.g. the association between marriage and childbearing and contraception. Third, future research - not only demographic studies - needs to discuss appropriate indicators regarding what constitutes a "minority culture", especially if integration processes over more than two generations are to be investigated, and it needs to develop theoretical frameworks for demographic processes and change in multicultural societies.

\section{Acknowledgments}

We are thankful to Erik Carlsson and Martin Radtke for their contributions to the literature overview. This research was supported by the Linnaeus Center on Social Policy and Family Dynamics in Europe (SPaDE), grant registration number 349-2007-8701; the Swedish Research Council for Health, Working Life and Welfare (Forte), grant number 2016-07105 and 2018-00310; and the Swedish Research Council (Vetenskapsrådet), grant number 2017-01021. We thank the CPoS editorial board for their support in planning and developing this Special Issue as well as all the anonymous reviewers that improved this introductory chapter and the articles included in this collection.

\section{References}

Abbasi-Shavazi, Mohammed Jalal; McDonald, Peter 2000: Fertility and Multiculturalism: Immigrant Fertility in Australia, 1977-1991. In: International Migration Review 34,1: 215-242 [doi: 10.1177/019791830003400109].

Abrevaya, Jason 2009: Are There Missing Girls in the United States? Evidence from Birth Data. In: American Economic Journal: Applied Economics 1,2: 1-34 [doi: 10.1257/ app.1.2.1].

Afulani, Patience A.; Asunka, Joseph 2015: Socialization, Adaptation, Transnationalism, and the Reproductive Behavior of Sub-Saharan African Migrants in France. In: Population Research and Policy Review 34,4: 561-592 [doi: 10.1007/s11113-015-9360-2].

Agadjanian, Victor; Yoo, Sam Hyun 2018: Migration, Legality, and Fertility Regulation: Abortion and Contraception among Migrants and Natives in Russia. In: Demographic Research 38,42: 1277-1302 [doi: 10.4054/DemRes.2018.38.42].

Ajzen, Icek; Klobas, Jane 2013: Fertility Intentions: An Approach Based on the Theory of Planned Behavior. In: Demographic Research 29,8: 203-232 [doi: 10.4054/DemRes.2013.29.8].

Algan, Yannet al. (Eds.) 2012: Cultural Integration of Immigrants in Europe. Oxford: Oxford University Press. 
Almond, Douglas; Edlund, Lena 2008: Son-biased Sex Ratios in the 2000 United States Census. In: Proceedings of the National Academy of Sciences of the United States of America 105,15: 5681-5682 [doi: 10.1073/pnas.0800703105].

Almond, Douglas; Edlund, Lena; Milligan, Kevin 2013: Son Preference and the Persistence of Culture: Evidence from South and East Asian Immigrants to Canada. In: Population and Development Review 39,1: 75-95 [doi: 10.1111/j.1728-4457.2013.00574.x].

Ambrosetti, Elena et al. 2015: Sex Imbalances at Birth in Migratory Context: Evidence from Italy. In: Genus 71,2-3: 29-51.

Andersson, Gunnar 2004: Childbearing after Migration: Fertility Patterns of Foreignborn Women in Sweden. In: International Migration Review 38,2: 747-774 [doi: 10.1111/ j.1747-7379.2004.tb00216.x].

Andersson, Gunnar et al. 2006: Gendering Family Composition: Sex Preferences for Children and Childbearing Behavior in the Nordic Countries. In: Demography 43,2: 255-267 [doi: 10.1353/dem.2006.0010].

Andersson, Gunnar; Hank, Karsten; Vikat, Andres 2007: Understanding Parental Gender Preferences in Advanced Societies: Lessons from Sweden and Finland. In: Demographic Research 17,6: 135-156 [doi: 10.4054/DemRes.2007.17.6].

Andersson, Gunnar; Hoem, Jan M.; Duvander, Ann Zofie 2006: Social Differentials in Speed-premium Effects in Childbearing in Sweden. In: Demographic Research 14,4: 51-70 [doi: 10.4054/DemRes.2006.14.4].

Andersson, Gunnar; Scott, Kirk 2005: Labour-market Status and First-time Parenthood: The Experience of Immigrant Women in Sweden, 1981-97. In: Population Studies 59,1: 21-38 [doi: 10.1080/0032472052000332683].

Andersson, Gunnar; Scott, Kirk 2007: Childbearing Dynamics of Couples in a Universalistic Welfare State: The Role of Labor-market Status, Country of Origin, and Gender. In: Demographic Research 17,30: 897-938 [doi: 10.4054/DemRes.2007.17.30].

Bankole, Akinriola; Singh, Susheela; Haas, Taylor 1998: Reasons Why Women Have Induced Abortions: Evidence from 27 Countries. In: International Family Planning Perspectives 24,3: 117-127 \& 152.

Barber, Jennifer S.; Yarger, Jennifer Eckerman; Gatny, Heather H. 2015: Black-White Differences in Attitudes Related to Pregnancy Among Young Women. In: Demography 52,3: 751-786 [doi: 10.1007/s13524-015-0391-4].

Baykara-Krumme, Helen; Milewski, Nadja 2017: Fertility Patterns Among Turkish Women in Turkey and Abroad: The Effects of International Mobility, Migrant Generation, and Family Background. In: European Journal of Population 33,3: 409-436 [doi: 10.1007/ s10680-017-9413-9].

Bean, Frank D.; Tienda, Marta 1990: The Hispanic Population of the United States. New York: Russell Sage Foundation.

Beauchemin, Cris (Ed.) 2018: Migration between Africa and Europe. Springer International Publishing. Cham: Springer [doi: 10.1007/978-3-319-69569-3].

Berrington, Ann 2018: Expectations for Family Transitions in Young Adulthood among the UK Second Generation. In: Journal of Ethnic and Migration Studies: 1-23 [doi: 10.1080/1369183X.2018.1539276].

Carlson, Elwood D. 1985: Increased Nonmarital Births among Foreign Women in Germany. In: Sociology and Social Research 70: 110-111.

Carlsson, Erik 2018: Fertility Intentions across Immigrant Generations in Sweden. Do Patterns of Adaptation Differ by Gender and Origin? In: Comparative Population Studies 43: 211-242 [doi: 10.12765/CPoS-2019-02en]. 
Carol, Sarah; Milewski, Nadja 2017: Attitudes Toward Abortion among the Muslim Minority and Non-Muslim Majority in Cross-national Perspective: Can Religiosity Explain the Differences? In: Sociology of Religion 78,4: 456-491 [doi: 10.1093/socrel/srx015].

Caselli, Marco 2015: Measuring the Integration of Immigrants: Critical Notes from an Italian Experience. In: International Migration 53,4: 107-119 [doi: 10.1111/imig.12011].

Coleman, David A. 1994: Trends in Fertility and Intermarriage among Immigrant Populations in Western Europe as Measures of Integration. In: Journal of Biosocial Science 26,1: 107-136 [doi: 10.1017/S0021932000021106].

Crul, Maurice; Schneider, Jens; Lelie, Frans (Eds.) 2012: The European Second Generation Compared: Does the Integration Context Matter? Amsterdam University Press.

Daugherty, Jill 2016: How Young Men at High Risk of Fathering an Unintended Birth Talk about their Procreative Identities. In: Journal of Family Issues 37,13: 1817-1842 [doi: 10.1177/0192513X14551176].

Deardorff, Julianna et al. 2010: Sexual Values and Risky Sexual Behaviors among Latino Youths. In: Perspectives on Sexual and Reproductive Health 42,1: 23-32 [doi: 10.1363/4202310].

Dehlendorf, Christine et al. 2011: Race, Ethnicity and Differences in Contraception Among Low-Income Women: Methods Received By Family PACT Clients, California, 2001-2007. In: Perspectives on Sexual and Reproductive Health 43,3: 181-187 [doi: 10.1363/4318111].

Diehl, Claudia; Koenig, Matthias 2009: Religiosität Türkischer Migranten im Generationenverlauf: Ein Befund und einige Erklärungsversuche. In: Zeitschrift für Soziologie 38, 300-319.

Diehl, Claudia; Koenig, Matthias; Ruckdeschel, Kerstin 2009: Religiosity and Gender Equality: Comparing Natives and Muslim Migrants in Germany. In: Ethnic and Racial Studies 32,2: 278-301 [doi: 10.1080/01419870802298454].

Dubuc, Sylvie; Coleman, David 2007: An Increase in the Sex Ratio of Births to India-born Mothers in England and Wales: Evidence for Sex-selective Abortion. In: Population and Development Review 33,2: 383-400 [doi: 10.1111/j.1728-4457.2007.00173.x].

Elder, Glen H. 1985: Perspectivess on the Life Course. In: Glen, H. Elder (Ed.): Life Course Dynamics: Trajectories and Transitions, 1968-1980. Ithaca: Cornell University Press: 23-49.

Elwert, Annika 2018: Will you Intermarry me? Determinants and Consequences of Immigrant-native Intermarriage in Contemporary Nordic settings. Lund: Lund University.

Eurostat 2002: Statistics in Focus. Statistics in Focus, Population and Social Conditions, Theme 3 [https://ec.europa.eu/eurostat/documents/3433488/5493259/KS-NK-02-017EN.PDF/66887d8d-0ef4-4cc8-8edd-42b3d41b1900?version=1.0, 19.03.2019].

Eurostat 2016: First and Second-generation Immigrants - Statistics on Main Characteristics. Eurostat Statistics Explained 2016 [https://ec.europa.eu/eurostat/statistics-explained/index.php/First_and_second-generation_immigrants_-_statistics_on_main_ characteristics, 19.03.2019].

Eurostat 2018: Migration and Migrant Population Statistics. Eurostat Statistics Explained 2018 [https://ec.europa.eu/eurostat/statistics-explained/index.php/Migration_and_ migrant_population_statistics, 19.03.2019].

Fernández, Raquel; Fogli, Alessandra 2006: Fertility: The Role of Culture and Family Experience. In: Journal of the European Economic Association 4,2-3: 552-561 [doi: 10.1162/jeea.2006.4.2-3.552]. 
FitzGerald, David 2012: A Comparativist Manifesto for International Migration Studies. In: Ethnic and Racial Studies 35,10: 1725-1740 [doi: 10.1080/01419870.2012.659269].

Forste, Renata; Tienda, Marta 1996: What's Behind Racial and Ethnic Fertility Differentials? In: Population and Development Review 22: 109-133 [doi: 10.2307/2808008].

Glick, Jennifer E. 2010: Connecting Complex Processes: A Decade of Research on Immigrant Families. In: Journal of Marriage and Family 72,3: 498-515 [doi: 10.1111/j.17413737.2010.00715.x, 19.03.2019].

González, Libertad 2014: Missing Girls in Spain. Working Papers 760. Barcelona Graduate School of Economics [https://ideas.repec.org/p/bge/wpaper/760.html, 05.07.2019].

Gordon, Milton 1964: Assimilation in American Life: The Role of Race, Religion, and National Origins [https://www.questia.com/library/120086644/assimilation-in-americanlife-the-role-of-race, 19.03.2019].

Güveli, Ayse et al. 2016: Intergenerational Consequences of Migration - Socio-economic, Family and Cultural Patterns of Stability and Change in Turkey and Europe. Hampshire: Palgrave [doi: 10.1057/9781137501424].

Hampshire, Kate; Blell, Mwenza; Simpson, Bob 2012: Navigating New Socio-demographic Landscapes: Using Anthropological Demography to Understand the 'Persistence' of High and Early Fertility among British Pakistanis. In: European Journal of Population 28,1: 39-63 [doi: 10.1007/s10680-011-9252-z].

Hartnett, Caroline Sten 2014: White-Hispanic Differences in Meeting Lifetime Fertility Intentions in the U.S. In: Demographic research 30,43: 1245-1276 [doi: 10.4054/DemRes.2014.30.43].

Haug, Sonja; Milewski, Nadja 2018: Women's Attitudes toward Assisted Reproductive Technologies - A Pilot Study among Migrant Minorities and Non-migrants in Germany. In: Comparative Population Studies 43: 343-370 [doi: 10.12765/CPoS-2019-06en].

Hayford, Sarah R.; Agadjanian, Victor 2011: Uncertain Future, Non-numeric Preferences, and the Fertility Transition: A Case Study of Rural Mozambique. In: Etude de la population africaine $=$ African population studies 25,2: 419-439.

Hayford, Sarah R.; Guzzo, Karen Benjamin 2013: Racial and Ethnic Variation in Unmarried Young Adults' Motivation to Avoid Pregnancy. In: Perspectives on Sexual and Reproductive Health 45,1: 41-51 [doi: 10.1363/4504113].

Helström, Lotti et al. 2003: Abortion Rate and Contraceptive Practices in Immigrant and Native Women in Sweden. In: Scandinavian Journal of Public Health 31,6: 405-410 [doi: 10.1080/14034940210165181].

Helström, Lotti; Zätterström, Catharina; Odlind, Viveca 2006: Abortion Rate and Contraceptive Practices in Immigrant and Swedish Adolescents. In: Journal of Pediatric and Adolescent Gynecology 19,3: 209-213 [doi: 10.1016/j.jpag.2006.02.007].

Hoksbergen, Harm; Tillie, Jean 2015: EURISLAM Codebook Survey-Data (WP-III). Amsterdam: AUP.

Holland, Jennifer A.; de Valk, Helga A. G. 2013: Ideal Ages for Family Formation among Immigrants in Europe. In: Advances in Life Course Research 18,4: 257-269 [doi: 10.1016/j.alcr.2013.08.002].

Jacobs, Josephine; Stanfors, Maria 2013: Racial and Ethnic Differences in U.S. Women's Choice Of Reversible Contraceptives, 1995-2010. In: Perspectives on Sexual and Reproductive Health 45,3: 139-147 [doi: 10.1363/4513913].

Kaa, Dirk J. van de 2001: Postmodern Fertility Preferences: From Changing Value Orientation to New Behavior. In: Population and Development Review 27: 290-331. 
Kahn, Joan R. 1994: Immigrant and Native Fertility During the 1980s: Adaptation and Expectations for the Future. In: International Migration Review 28,3: 501-519 [doi: 10.1177/019791839402800304].

Kalmijn, Matthijs; Kraaykamp, Gerbert 2017: Determinants of Cultural Assimilation in the Second Generation. A Longitudinal Analysis of Values about Marriage and Sexuality among Moroccan and Turkish Migrants. In: Journal of Ethnic and Migration Studies 44,5: 697-717 [doi: 10.1080/1369183X.2017.1363644].

Kes/er, Christe/ 2006: Social Policy and Immigrant Joblessness in Britain, Germany and Sweden. In: Social Forces 85,2: 743-770 [doi: 10.1353/sof.2007.0013].

Kogan, Irena 2003: Ex-Yugoslavs in the Austrian and Swedish Labour Markets: The Significance of the Period of Migration and the Effect of Citizenship Acquisition. In: Journal of Ethnic and Migration Studies 29,4: 595-622 [doi: 10.1080/1369183032000123413].

Krapf, Sandra; Wolf, Katharina 2015: Persisting Differences or Adaptation to German Fertility Patterns? First and Second Birth Behavior of the 1.5 and Second Generation Turkish Migrants in Germany. In: Kölner Zeitschrift für Soziologie und Sozialpsychologie 67, Supplement 1: 137-164 [doi: 10.1007/s11577-015-0331-8].

Kraus, Elisabeth K.; Castro-Martín, Teresa 2018: Does Migrant Background Matter for Adolescents' Fertility Preferences? The Latin American 1.5 Generation in Spain. In: European Journal of Population 34,3: 277-312 [doi: 10.1007/s10680-017-9427-3].

Kuhnt, Anne-Kristin; Kreyenfeld, Michaela; Trappe, Heike 2017: Fertility Ideals of Women and Men Across the Life Course. In: Kreyenfeld, Michaela; Konietzka, Dirk: Childlessness in Europe: Contexts, Causes, and Consequences. Demographic Research Monographs. Cham: Springer International Publishing: 235-251 [doi: 10.1007/978-3319-44667-7_11].

Kulu, Hill; González-Ferrer, Amparo 2014: Family Dynamics among Immigrants and Their Descendants in Europe: Current Research and Opportunities. In: European Journal of Population 30,4: 411-435 [doi: 10.1007/s10680-014-9322-0].

Kulu, Hill; Hannemann, Tina 2016: Why does fertility remain high among certain UK-born ethnic minority women? In: Demographic Research 35,49: 1441-1488 [doi: 10.4054/ DemRes.2016.35.49].

Kulu, Hill et al. 2017: Fertility by Birth Order among the Descendants of Immigrants in Selected European Countries. In: Population and Development Review 43,1: 31-60 [doi: 10.1111/padr.12037].

Kulu, Hill; Milewski, Nadja 2007: Family Change and Migration in the Life Course: An Introduction. In: Demographic Research 17,19: 567-590 [doi: 10.4054/DemRes.2007.17.19].

Kusunoki, Yasamin et al. 2016: Black-White Differences in Sex and Contraceptive Use Among Young Women. In: Demography 53,5: 1399-1428 [doi: 10.1007/s13524-0160507-5].

Lillehagen, Mats; Lyngstad, Torkild Hovde 2018: Immigrant Mothers' Preferences for Children's Sexes: A Register-based Study of Fertility Behaviour in Norway. In: Population Studies 72,1: 91-107 [doi: 10.1080/00324728.2017.1421254].

Mayer, Jochen; Riphahn, Regina T. 2000: Fertility Assimilation of Immigrants: Evidence from Count Data Models. In: Journal of Population Economics 13,2: 241-261 [doi: 10.1007/s001480050136].

Milewski, Nadja 2007: First Child of Immigrant Workers and their Descendants in West Germany: Interrelation of Events, Disruption, or Adaptation? In: Demographic Research 17,29: 859-896 [doi: 10.4054/DemRes.2007.17.29]. 
Milewski, Nadja 2010: Fertility of Immigrants. A Two-generational Approach in Germany. Berlin/Heidelberg: Springer [doi: 10.1007/978-3-642-03705-4].

Milewski, Nadja 2011: Transition to a First Birth among Turkish Second-generation Migrants in Western Europe. In: Advances in Life Course Research 16,4: 178-189 [doi: 10.1016/j.alcr.2011.09.002].

Milewski, Nadja; Carol, Sarah 2018: Attitudes toward Abortion for Medical and Nonmedical Reasons among the Turkish Second Generation in Europe - The Role of the Family and Societal Contexts. In: Comparative Population Studies 43: 307-342 [doi: 10.12765/CPoS-2019-05en].

Miller, Grant; Valente, Christine 2016: Population Policy: Abortion and Modern Contraception Are Substitutes. In: Demography 53,4: 979-1009 [doi: 10.1007/s13524-0160492-8].

Miller, Warren B.; Pasta, David J. 1995: Behavioral Intentions: Which Ones Predict Fertility Behavior in Married Couples? In: Journal of Applied Social Psychology 25,6: 530 555 [doi: 10.1111/j.1559-1816.1995.tb01766.x].

Miranda, Vitor; Dahlberg, Johan; Andersson, Gunnar 2018: Parents' Preferences for Sex of Children in Sweden: Attitudes and Outcomes. In: Population Research and Policy Review 37,3: 443-459 [doi: 10.1007/s11113-018-9462-8].

Mussino, Eleonora et al. 2012: II Comportamento Riproduttivo e le Strategie Migratorie degli Stranieri Presenti in Lombardia. In: Rivista Italiana di Economia, Demografia e Statistica LXVI,1: 197-204.

Mussino, Eleonora; Miranda, Vitor; Ma, Li 2018: Changes in Sex Ratio at Birth among Immigrant Groups in Sweden. In: Genus 74,1: 13 [doi: 10.1186/s41118-018-0036-8].

Mussino, Eleonora; Miranda, Vitor; Ma, Li 2019: Transition to third birth among immigrant mothers in Sweden: Does having two daughters accelerate the process? In: Journal of Population Research 36,2: 81-109 [doi: 10.1007/s12546-019-09224-x].

Mussino, Eleonora; Ortensi, Livia Elisa 2018: The Same Fertility Ideals as in the Country of Origin? A Study of the Personal Ideal Family Size among Immigrant Women in Italy. In: Comparative Population Studies 43: 243-274 [doi: 10.12765/CPoS-2019-03en].

Mussino, Eleonora; Strozza, Salvatore; Terzera, Laura 2014: II Ruolo delle Variabili Individuali e delle Realtà D'insediamento Nell'integrazione degli Immigrati. In: Donadio, Paolo; Gabrielli, Giuseppe; Massari, Monica: Uno Come te. Europei e Nuovi Europei nei Percorsi di Integrazione. Mailand: FrancoAngeli: 119-130.

Mussino, Eleonora; Tervola, Jussi; Duvander, Ann-Zofie 2018: Decomposing the Determinants of Fathers' Parental Leave Use: Evidence from Migration between Finland and Sweden. In: Journal of European Social Policy [doi: 10.1177/0958928718792129].

Namboodiri, N. Krishnan 1983: Sequential Fertility Decision-Making and the Life Course. In: Bulatao, Rodolfo A.; Lee, Ronald D.: Determinants of Fertility in Developing Countries. New York: Academic Press: 444-472.

Penn, Roger; Lambert, Paul 2002: Attitudes Towards Ideal Family Size of Different Ethnic/Nationality Groups in Great Britain, France and Germany. In: Population trends 108: 49-58.

Penninx, Rinus 2005: Integration of Migrants: Economic, Social, Cultural and Political Dimensions. In: Macura, Miroslav; MacDonald, Iphonse L.; Haug, Werner: The New Demographic Regime Population Challenges and Policy Responses. New York/Geneva: United Nations Publications: 137-152. 
Pew Research Center 2017: Europe's Growing Muslim Population. In: Religion \& Public Life 2017 [http://www.pewforum.org/2017/11/29/europes-growing-muslim-population/, 09.04.2019].

Philipov, Dimiter; Bernardi, Laura 2011: Concepts and Operationalisation of Reproductive Decisions Implementation in Austria, Germany and Switzerland. In: Comparative Population Studies 36,2-3: 495-530 [doi: 10.4232/10.CPoS-2011-14en].

Poncet, Lorraine Catherine et al. 2013: Contraceptive Use and Method among Immigrant Women in France: Relationship with Socioeconomic Status. In: The European Journal of Contraception \& Reproductive Health Care 18,6: 468-479 [doi: 10.3109/13625187.2013.835394].

Präg, Patrick; Mills, Melinda C. 2017a: Assisted Reproductive Technology in Europe: Usage and Regulation in the Context of Cross-Border Reproductive Care. In: Kreyenfeld, Michaela; Konietzka, Dirk: Childlessness in Europe: Contexts, Causes, and Consequences. Cham: Springer International Publishing: 289-309 [doi: 10.1007/9783-319-44667-7_14].

Präg, Patrick; Mills, Melinda C. 2017b: Cultural Determinants Influence Assisted Reproduction Usage in Europe More than Economic and Demographic Factors. In: Human Reproduction 32,11: 2305-2314 [doi: 10.1093/humrep/dex298].

Puri, Sunita et al. 2011: “There Is Such a Thing as Too Many Daughters, but Not Too Many Sons": A Qualitative Study of Son Preference and Fetal Sex Selection among Indian Immigrants in the United States. In: Social Science \& Medicine 72,7: 1169-1176 [doi: 10.1016/j.socscimed.2011.01.027].

Puur, Allan et al. 2017: Childbearing among First- and Second-generation Russians in Estonia against the Background of the Sending and Host Countries. In: Demographic Research 36,41: 1209-1254 [doi: 10.4054/DemRes.2017.36.41].

Puur, Allan; Vseviov, Hanna; Abuladze, Liili 2018: Fertility Intentions and Views on Gender Roles: Russian Women in Estonia from an Origin-destination Perspective. In: Comparative Population Studies 43: 275-306 [doi: 10.12765/CPoS-2019-04en].

Ray, Joel G.; Henry, David A.; Urquia, Marcelo L. 2012: Sex Ratios among Canadian Liveborn Infants of Mothers from Different Countries. In: CMAJ: Canadian Medical Association Journal 184,9: E492-E496 [doi: 10.1503/cmaj.120165].

Rocca Corinne H. et al. 2010: Predictive Ability and Stability of Adolescents' Pregnancy Intentions in a Predominantly Latino Community. In: Studies in Family Planning 41,3: 179-192 [doi: 10.1111/j.1728-4465.2010.00242.x].

Sedgh, Gilda et al. 2016: Abortion Incidence between 1990 and 2014: Global, Regional, and Subregional Levels and Trends. In: The Lancet 388: 258-267 [doi: 10.1016/S01406736(16)30380-4].

Singh, Narpinder et al. 2010: Different Sex Ratios of Children Born to Indian and Pakistani Immigrants in Norway. In: BMC Pregnancy and Childbirth 10,1: 40 [doi: 10.1186/14712393-10-40].

Sobotka, Tomáš 2008: Overview chapter 7: The Rising Importance of Migrants for Childbearing in Europe. In: Demographic Research 19,9: 225-248 [doi: 10.4054/DemRes.2008.19.9].

Sobotka, Tomáš; Beaujouan, Éva 2014: Two Is Best? The Persistence of a Two-Child Family Ideal in Europe. In: Population and Development Review 40,3: 391-419 [doi: 10.1111/j.1728-4457.2014.00691.x].

Sonnino, Eugenio 2003: La Popolazione Straniera in Italia (1986-1996): Matrimoni, Nascite e Stime di Fecondità. Rom: Universit' Di Roma La Spaienza-dipartimento di scienze demografiche-Fonti e strumenti 5. 
Sorenson, Ann Marie 1985: Fertility Expectations and Ethnic Identity among MexicanAmerican Adolescents: An Expression of Cultural Ideals. In: Sociological Perspectives 28,3: 339-360 [doi: 10.2307/1389151].

Spierings, Niels 2015: Gender Equality Attitudes among Turks in Western Europe and Turkey: The Interrelated Impact of Migration and Parents' Attitudes. In: Journal of Ethnic and Migration Studies 41,5: 749-771.

Testa, Maria Rita; Grilli, Leonardo 2006a: L'influence des Différences de Fécondité dans les Régions Européennes sur la Taille Idéale de la Famille. In: Population 61,1: 107-137 [doi: 10.3917/popu.601.0107].

Testa, Maria Rita; Grilli, Leonardo 2006b: The Influence of Childbearing Regional Contexts on Ideal Family Size in Europe. In: Population (english edition) 61,1: 109-137 [doi: 10.3917/pope.601.0099].

Thomson, Elizabeth 2015: Family Size Preferences. In: Wright, James D. (Ed.): International Encyclopedia of the Social \& Behavioral Sciences (Second Edition). Oxford: Elsevier: 805-808 [doi: 10.1016/B978-0-08-097086-8.31064-9].

Toulemon, Laurent 2004: La Fécondité des Immigrées: Nouvelles Données, Nouvelle Approche. In: Population \& Societes 400 [https://www.ined.fr/fichier/s_rubrique/18833/ pop_et_soc_francais_400.fr.pdf, 09.04.2019].

Toulemon, Laurent; Testa, Maria Rita 2005: Fertility Intentions and Actual Fertility: A Complex Relationship. In: Population \& Societies 415 [https://www.ined.fr/fichier/s_ rubrique/18747/publi_pdf2_pop.and.soc.english.415.en.pdf, 09.04.2019].

Trent, Roger B. 1980: Evidence Bearing on the Construct Validity of ,Ideal Family Size'. In: Population and Environment 3,3/4: 309-327.

Triandafyllidou, Anna; Gropas, Ruby (Eds.) 2007: European Immigration: A Sourcebook. Hampshire: Ashgate Publishing Limited.

Tubergen, Frank van; Maas, Ineke; Flap, Henk 2004: The Economic Incorporation of Immigrants in 18 Western Societies: Origin, Destination, and Community Effects. In: American Sociological Review 69,5: 704-727 [doi: 10.1177/000312240406900505].

Valk, Helga A. G. de 2013: Intergenerational Discrepancies in Fertility Preferences among Immigrant and Dutch families. In: The History of the Family 18,2: 209-225 [doi: 10.1080/1081602X.2013.826591].

Valk, Helga A. G. de; Milewski, Nadja 2011: Family Life Transitions among Children of Immigrants: An Introduction. In: Advances in Life Course Research 16,4: 145-151 [doi: 10.1016/j.alcr.2011.10.001].

Verropoulou, Georgia; Tsimbos, Cleon 2010: Differentials in Sex Ratio at Birth among Natives and Immigrants in Greece: An Analysis Employing Nationwide Micro-Data. In: Journal of Biosocial Science 42;3: 425-430 [doi: 10.1017/S0021932009990599].

White, Kari; Potter, Joseph E. 2013: Patterns of Contraceptive Use among MexicanOrigin Women. In: Demographic Research 28,41: 1199-1212 [doi: 10.4054/DemRes.2013.28.41].

WHO (World Health Organization) 2005: The World Health Report 2005. Make Every Mother and Child Count. Geneva: World Health Organization.

Wilson, Ben 2018: The Intergenerational Assimilation of Completed Fertility: Comparing the Convergence of Different Origin Groups. In: International Migration Review [doi: 10.1177/0197918318769047].

Wilson, Deborah; Burgess, Simon; Briggs, Adam 2011: The Dynamics of School Attainment of England's Ethnic Minorities. In: Journal of Population Economics 24,2: 681700 [doi: 10.1007/s00148-009-0269-0]. 


\section{Appendix}

Tab. A1: Journals included in our literature review

Covering general demography/ population studies

Advances in Life Course Research

Demographic Research

Demography

European Journal of Population

Journal of Population Economics

Population

Population and Development Review

Population and Environment

Population Research and Policy Review

Population Studies

Population, Space and Place

Covering migration/migrant-related topics

International Migration Review

Journal of Ethnic and Migration Studies

Journal of Refugee Studies

Covering family/ fertility/ sexuality related topics

International Perspectives on Sexual and Reproductive Health

Journal of Biosocial Science

Journal of Family Issues

Journal of Marriage and Family

Perspectives on Sexual and Reproductive Health

Studies in Family Planning

Social Science and Medicine

Prof. Dr. Nadja Milewski ( $\triangle)$. University of Rostock, Institute of Sociology and Demography. Rostock, Germany. E-mail: nadja.milewski@uni-rostock.de URL: https://www.isd.uni-rostock.de/en/isd/lehrstuhl/jp-demo/milewski/

Eleonora Mussino. Stockholm University. Stockholm, Sweden.

E-mail: eleonora.mussino@sociology.su.se

URL: https://www.su.se/english/profiles/emuss-1.189704 


\section{Comparative Population Studies}

WWW.comparativepopulationstudies.de

ISSN: 1869-8980 (Print) - 1869-8999 (Internet)

\section{Published by}

Prof. Dr. Norbert F. Schneider

Federal Institute for Population Research D-65180 Wiesbaden / Germany

\section{(cc) BY-SA}

2018

\section{Managing Editor}

Dr. Katrin Schiefer

\section{Copy Editor}

Dr. Evelyn Grünheid

Dr. Katrin Schiefer

\section{Editorial Assistant}

Beatriz Feiler-Fuchs

Wiebke Hamann

\section{Layout \\ Beatriz Feiler-Fuchs \\ E-mail:cpos@bib.bund.de}

\section{Scientific Advisory Board}

Karsten Hank (Cologne)

Michaela Kreyenfeld (Berlin)

Marc Luy (Vienna)

Peter Preisendörfer (Mainz)

Nikola Sander (Wiesbaden)

Zsolt Spéder (Budapest)

Rainer Wehrhahn (Kiel)

\section{Board of Reviewers}

Martin Abraham (Erlangen)

Laura Bernardi (Lausanne)

Hansjörg Bucher (Bonn)

Claudia Diehl (Konstanz)

Andreas Diekmann (Zurich)

Gabriele Doblhammer-Reiter (Rostock)

Jürgen Dorbritz (Wiesbaden)

Anette Eva Fasang (Berlin)

E.-Jürgen Flöthmann (Bielefeld)

Alexia Fürnkranz-Prskawetz (Vienna)

Beat Fux (Salzburg)

Joshua Goldstein (Berkeley)

Sonja Haug (Regensburg)

Hill Kulu (Liverpool)

Aart C. Liefbroer (The Hague)

Kurt Lüscher (Konstanz)

Emma Lundholm (Umeå)

Nadja Milewski (Rostock)

Dimiter Philipov (Vienna)

Roland Rau (Rostock)

Tomáš Sobotka (Vienna)

Jeroen Spijker (Barcelona)

Olivier Thévenon (Paris)

Helga de Valk (Brussels)

Heike Trappe (Rostock)

Michael Wagner (Cologne) 